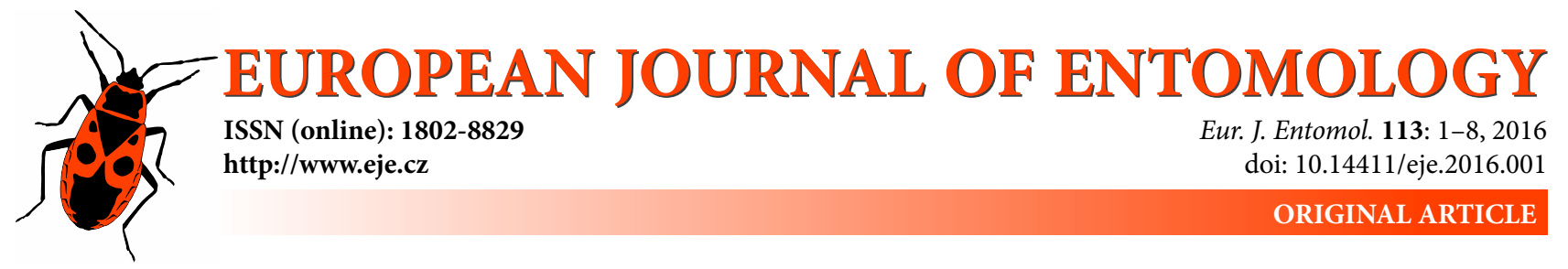

\title{
Fine fluorescent powder marking study of dispersal in the spruce bark beetle, Ips typographus (Coleoptera: Scolytidae)
}

\author{
Petr DOLEŽAL ${ }^{1,2, *}$, Jan OKROUHLíK ${ }^{1,2, *}$ and Markéta DAVÍDKOVÁ ${ }^{1,2}$ \\ ${ }^{1}$ Institute of Entomology, Biology Centre of the Czech Academy of Sciences, Branišovská 31, 37005 České Budějovice, \\ Czech Republic; e-mails: dolezal@entu.cas.cz, marketadavidkova@seznam.cz \\ ${ }^{2}$ Faculty of Science, University of South Bohemia, Branišovská 1760, 37005 České Budějovice, Czech Republic; \\ e-mail: jan.okrouhlik@prf.jcu.cz
}

Key words. Coleoptera, Scolytidae, Ips typographus, bark beetle, dispersal, fluorescent powder, protected areas

\begin{abstract}
A novel method was used to study dispersal in the spruce bark beetle, Ips typographus (L.), under epidemic conditions (rapidly increasing population density) in the Šumava National Park. Infested spruce logs were coated with a fine fluorescent powder and the passively marked emerging beetles were captured in pheromone baited traps located at various distances from these logs. The number of marked beetles captured decreased exponentially with increasing distance from the release point. The sex ratio of the bark beetles was more female biased the further they were recaptured from the logs, being $57 \%$ and $60 \%$ at distances of up to 50 and $100 \mathrm{~m}$, respectively. The maximum distance flown by a marked beetle recorded in this experiment was $1094 \mathrm{~m}$. A model fitted to the data on dispersal indicates that $10 \%$ of the spruce bark beetles dispersed over distances of $55 \mathrm{~m}$ and $4 \mathrm{~m}$ in spring (overwintered parental generation) and summer (first filial generation), respectively. Differences between spring and summer swarming are briefly discussed.
\end{abstract}

\section{INTRODUCTION}

Even-aged monocultures of Norway spruce (Picea abies) are the main type of forests planted in the Czech Republic (Spiecker, 2003; Knoke et al., 2005; Yousefpour et al., 2010; Mansfeld, 2011). The transformation of natural mixed forests to spruce monocultures has led to changes in forest structure and composition as well as the spread of Norway spruce beyond its natural distribution (Knoke et al., 2005). As a consequence, forest managers are facing decreased resistance of stands to various biotic (insects, fungi) and abiotic (snow, storms, drought) factors (Spiecker, 2003).

The spruce bark beetle, Ips typographus (L.), is one of the most important forest pests in Central Europe (Reeve, 1997; Wermelinger \& Seifert, 1999; Wichmann \& Ravn, 2001). It is commonly considered to be a secondary pest of Norway spruce (Szujecki, 1987; Forster, 1993; Schwenke, 1996), but may occasionally infest also pine and larch. Dispersal of adults is a minor but key part in the life cycle, which may crucially influence the survival and reproductive success of the spruce bark beetle (Hawkes, 2009) and colonization of host trees (Kautz et al., 2011a). Before a host tree is infested, the adults exhibit a series of consecutive behaviours. According to Byers $(1996,2000)$, the ini- tial phase of each swarming is assumed to be a nonlinear random flight, which continues until beetles respond to attractive stimuli and/or wind drift starts to have an effect. Hietz et al. (2005) report there is a strong correlation between bark temperature and the emission of attractants from spruce trees. The final acceptance of a host spruce tree is probably further conditioned by visual signals, which may (in some bark beetle species) prevail where volatile stimuli are absent, weak or uninformative (Campbell \& Borden, 2009). The process of host tree acceptance is finally completed by a positive response of adults to gustatory stimuli and penetration into phloem of the tree (Raffa \& Berryman, 1982). Ips typographus prefers weakened, damaged or dying trees, predominantly older than 60 years. Favourable climatic conditions, frequently in combination with the late removal of infested timber, may lead to an outbreak of spruce bark beetles (Kautz et al., 2011a; Lausch et al., 2011). During such outbreaks, Ips typographus population density increases exponentially and emerging adults are able to infest and kill even healthy trees on a large scale, which changes Ips typographus into a primary pest (Reeve, 1997).

Because of the enormous economic losses caused by the spruce bark beetle, it is crucially important to have a

\footnotetext{
* Equal contribution.
} 
detailed knowledge of its life cycle as this will aid in the optimization of protective measures leading to reduced costs. Interestingly, there are several aspects of spruce bark beetle biology that remain unclear and on which there is disagreement in the scientific literature. Importantly, questions regarding the spatial dispersion of the spruce bark beetle are frequently raised but rarely resolved. Few studies on the dispersal of Ips typographus are published and they used different methods. Most of these studies record the maximum flight distance of Ips typographus. Based on the methodology used, these studies may be divided into several groups. The first group includes studies based on more or less random catches or observations of beetles at various distances from the closest infestations or spruce stand. Flight distances reported in these studies are frequently many kilometres. The greatest distance reported, $43 \mathrm{~km}$, is that in a study conducted by Nilssen (1984), who placed logs of spruce at various distances from the nearest spruce forest or bark beetle infestation and recorded the maximum distance at which individuals of various species of bark beetle were found. Nuorteva (1955) found adults of Ips typographus on pines approximately $60 \mathrm{~km}$ beyond the northern range of spruce in Finland. Fleischer (1875) and Komárek (1931) record spruce bark beetles flying from spruce stands and colonizing solitary spruce trees at distances of 20-30 km. The second group of studies used various methods of capture-mark-recapture, including several methods of marking the beetles prior to release. Duelli et al. (1997) used special pens to place coloured spots onto the pronotum of the beetles, which enabled the recaptured individuals to be sorted based on their release date. Every individual had to be marked manually, which made this method tedious and may also have influenced the behaviour and physiological status of the adults. Werner \& Holsten (1997) and Franklin et al. (2000) stained the beetles in a sealed container with fluorescent powder. Thus, the need to handle every specimen was eliminated, but shaking the container to ensure the beetles were coated with the powder may still have influenced their dispersal behaviour. Zumr (1990, 1991, and 1992) captured adults in pheromone traps, marked them using a liquid fluorescent paint and then released them at two localities that differed in forest composition (mixed stand vs. spruce monoculture). He reported a relatively high percentage (63-65\%) of marked beetles in pheromone traps installed up to approximately $1.2 \mathrm{~km}$ from the release points at both localities. Duelli et al. (1997) studied two categories of adults, those with and without previous flight experience, and marked these with different colours. The adults were then recaptured in pheromone traps arranged in three concentric circles (10, 160 and $400 \mathrm{~m}$ in diameter) in a pine (Pinus sylvestris L.) stand. Most adults flew less than $500 \mathrm{~m}$ but flight distances of more than $6 \mathrm{~km}$ were also recorded. Forsse \& Solbreck (1985) tested the influence of energy reserves (stored lipid content) on flight distance. Measurements in flight mills indicated that Ips typographus adults can fly for distances of more than $19 \mathrm{~km}$. The authors also studied vertical distribution of flying beetles in the field using suction traps placed at four heights $(2,9,43$ and $93 \mathrm{~m}$ above ground) on a TV tower, which indicated that only $14 \%$ of the beetles flew higher than $20 \mathrm{~m}$ above the ground. Zolubas \& Byers (1995), who were the first to use fluorescent powder, recaptured marked adults in pheromone-baited traps placed at $10,30,60,90$ and $120 \mathrm{~m}$ from the release point.

A completely different approach is represented by the so called indirect methods. These methods are based on an analysis of aerial or satellite images of localities taken repeatedly several times a year. A comparison of such photographs provides information on successive activity of the pest and speed of its spreading through the canopy. Kautz et al. (2011b) analysed a dataset of infrared images documenting spruce bark beetle dispersion in the Bavarian Forest National Park since 1988. Similarly, Lausch et al. (2011, 2013) studied an 18 year dataset of colour-infrared aerial photographs of a selected part of the Bavarian Forest National Park. Both studies concluded that the new infestations occurred predominantly at distances of up to 500 $\mathrm{m}$ from previous ones. Indirect methods generate datasets on spatio-temporal scale but, unfortunately, with relatively low accuracy since the resolution of satellite images is not high enough to recognise a solitary infested tree. Moreover, it is impossible to identify the source of infestation and therefore the precise distance that the beetles flew before infesting a particular tree.

In the Czech Republic, the distance that Ips typographus can fly has become a political topic, mainly in relation to its recent outbreak in unmanaged parts of the Sumava National Park (Šumava NP). Šumava NP is part of the Bohemian Forest that occurs not only within the Czech Republic but also in Germany and Austria. The international character of the problem, together with the fact that neighbouring stands are predominantly commercial monocultures of spruce (except in the Bavarian Forest National Park in Germany), escalated the debate about the outbreak and spread of the spruce bark beetle and resulted in the Czech-Austrian governmental agreement that regulates the protective measures against Ips typographus in border areas.

The design of the current experiment was based on the above mentioned scientific literature. Marking the adults with fluorescent powder (detectable on bark beetle epidermis in amounts as low as one grain of $2 \mathrm{~nm}$ in diameter) increased the accuracy of flight distance measurements and the passive marking during emergence from logs also eliminated possible influence of handling on adult behaviour.

The aim of the present study was to test this method of marking and detection in outdoor conditions in the Sumava NP and determine the dispersal of Ips typographus, especially its spread from the unmanaged core zones to the surrounding intensively managed areas.

\section{MATERIAL AND METHODS}

\section{Study site}

The study area is within the Šumava National Park and Šumava Protected Landscape Area. Therefore, the process of site selection had to be a compromise between landscape characteristics and the relevant legislation (environmental law in the unmanaged core zone and forestry law in the surrounding areas). 


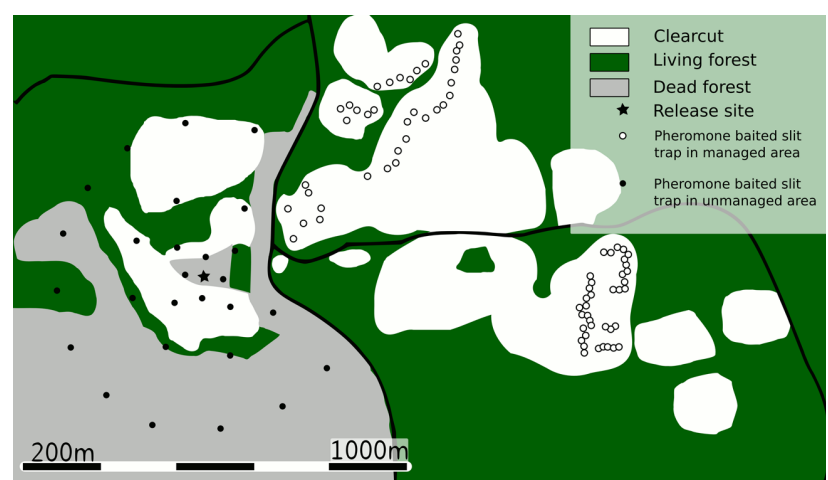

Fig. 1. Schematic map of the experimental site showing the location of the release point and the pheromone baited traps, which were periodically checked for the presence of marked beetles. The furthest clear cut with 24 pheromone baited traps, which was located about $3 \mathrm{~km}$ southwest of the release point, is not depicted. North is at the top of the map.

The experimental site $\left(49^{\circ} 03^{\prime} \mathrm{N}, 13^{\circ} 25^{\prime} \mathrm{E}, 1150 \mathrm{~m}\right.$ a.s.l.) is located in an unmanaged spruce-dominated forest in the core zone of the Šumava NP. The site consists of a large, south-facing deforested area $\left(20,000 \mathrm{~m}^{2}\right)$, in which all trees were felled by the hurricane "Kyrill" in 2007. The locality was declared part of the unmanaged core zone in 2008 and the deforested area is surrounded by $60-80$ year old spruce stands (Fig. 1 ). Its eastern side abuts on managed spruce forests and a barrier of pheromone-baited, poisoned spruce trunks was installed on the border in April 2013 to try to prevent the spread of beetles. The outbreak started in 2009 and resulted in an increasing proportion of dead standing trees. The volume of infested timber is not being monitored due to the conservation status of the locality, but an indication of the population density of the spruce bark beetle can be obtained from the maximum yearly catches of monitoring pheromone traps that reached 50,000 to 150,000 beetles per trap in the period 2009 2013. Air temperature at a sun exposed location was recorded at 30 min intervals using Commeter data loggers (Comet Systems, Rožnov pod Radhoštěm, Czech Republic).

\section{Insects, fluorescent marking and data collection}

A mark-release-recapture method was used to assess the flight distance of Ips typographus. To avoid physical damage during manipulation of beetles, a layer of fine fluorescent powder (Radglo JST-10, Radiant Color NV, Houthalen, Belgium) was dusted onto the surface of spruce logs, containing adult beetles, using a Birchmayer DR $5 \mathrm{CO}_{2}$-powered duster (Birchmeier Sprühtechnik AG, Stetten, Switzerland). Before flight, emerging beetles walk on the surface of the $\log$, which resulted in $100 \%$ of them being passively marked by fine grains of the fluorescent powder that adhered to cuticular hairs, especially those on the apex of the elytra. This enabled their detection in mass trapping devices and on trap trees. The release point was in the middle of the deforested area and 70 infested spruce logs were transferred to the release point in April/May 2013 (spring swarming / overwintered parental generation) and June/July 2013 (summer swarming / first filial generation). The logs were cut from infested trees located on this site. The row of standing logs dusted with fluorescent powder was then covered with a tin roof to prevent the powder from being washed off by rain. Ten logs were randomly selected as soon as the majority of beetles had emerged and debarked to estimate the number of beetles they had harboured.

A total of 124 Theysohn pheromone traps (TPTs) baited with FeSex Typo dispensers (Ubik Karel, Prague, Czech Republic) were installed around the release point. Four concentric circles (50, 100, 200 and $375 \mathrm{~m}$ in diameter), each circle consisting of
27 TPTs, surrounded the release point and the numbers of beetles they caught were used for modelling the dispersion. The remaining 97 TPTs were installed in clusters in the surrounding clear cut areas and stand edges at distances ranging from $250 \mathrm{~m}$ to $3051 \mathrm{~m}$ from the release point (see Fig. 1).

Traps were checked weekly or twice per week during sunny and warm periods, when swarming occurred, and total catch per trap was recorded. The sampling period began on May 6, 2013 and ended on Sept 16, 2013. The presence of marked beetles was detected by illumination using a portable blue light source (cca 1W Luxeon Rebel LED Royal-Blue, Quadica Developments Inc., Brantford, Canada fitted into a cheap CREE hand torch). Yellow goggles filtering out the blue excitation light were used to enhance the effect of illumination and make it easier to identify marked specimens (for detailed spectral characteristics, see Okrouhlík \& Foltan, 2015). Horizontal transfer of fluorescent powder onto unmarked specimens in TPTs was unlikely as shown during preliminary laboratory and field experiments performed in 2012 (Doležal \& Okrouhlík, unpubl. data). The sex of positively identified beetles was then assessed by dissection in the laboratory; however, this was possible only in about $69 \%$ of the cases. The remaining samples were too dry or too decomposed to be dissected.

\section{Dispersion modelling}

Only capture data within the unmanaged zone were used for dispersion modelling. The pooled numbers of marked Ips typographus captured in each circle were divided by the number of traps in a particular circle. The resulting numbers, i.e. marked beetles per trap at four distances, were fitted using the following the model:

$$
m S B B(d s t)=a \times\left(\mathrm{e}^{b \times d s t^{-\frac{2}{3}}}-1\right)
$$

where, $m S B B(d s t)$ is the predicted number of marked spruce bark beetles recaptured at distance $d s t$ from the release point, $e$ is the Euler number and $a$ and $b$ are estimated parameters of the model.

Model parameters were estimated using the Rosenbrock and quasi-Newton method with the following loss function: [ $\ln$ (pred) $-\ln (o b s)]^{2}$, where pred and obs were values predicted by the model and values actually observed, respectively. This loss function enabled more precise fitting of more distant circles as suggested by Turchin \& Thoeny (1993).

An estimated maximum distance dispersed by $50 \%$ and $10 \%$ (median and upper 10\% quantile of dispersion distance) of the marked beetles was calculated using the model as follows:

$$
y=100-\frac{\int_{x=50}^{\text {disp }} m S B B(x)}{\int_{x=50}^{1200} m S B B(x)}
$$

where $\operatorname{mSBB}(x)$ is the predicted number of marked spruce bark beetles recaptured at distance $x$ from the release point. We used the trapezoidal rule to calculate the definite integral with a step of 1. Starting with 51 , the parameter disp in the above equation was increased by one until the result $y$ reached approximately 50 and 10 , respectively.

To evaluate the potential threat of beetles dispersing from unmanaged into managed stands, capture rates predicted by the above model were compared to actual capture rates of the traps located in the neighboring managed area. Prior to analysis, these traps were divided into groups according to their distance from the release point. Mean distances of these groups from the release point were $375,520,700,900$ and $1100 \mathrm{~m}$. Counts of marked 

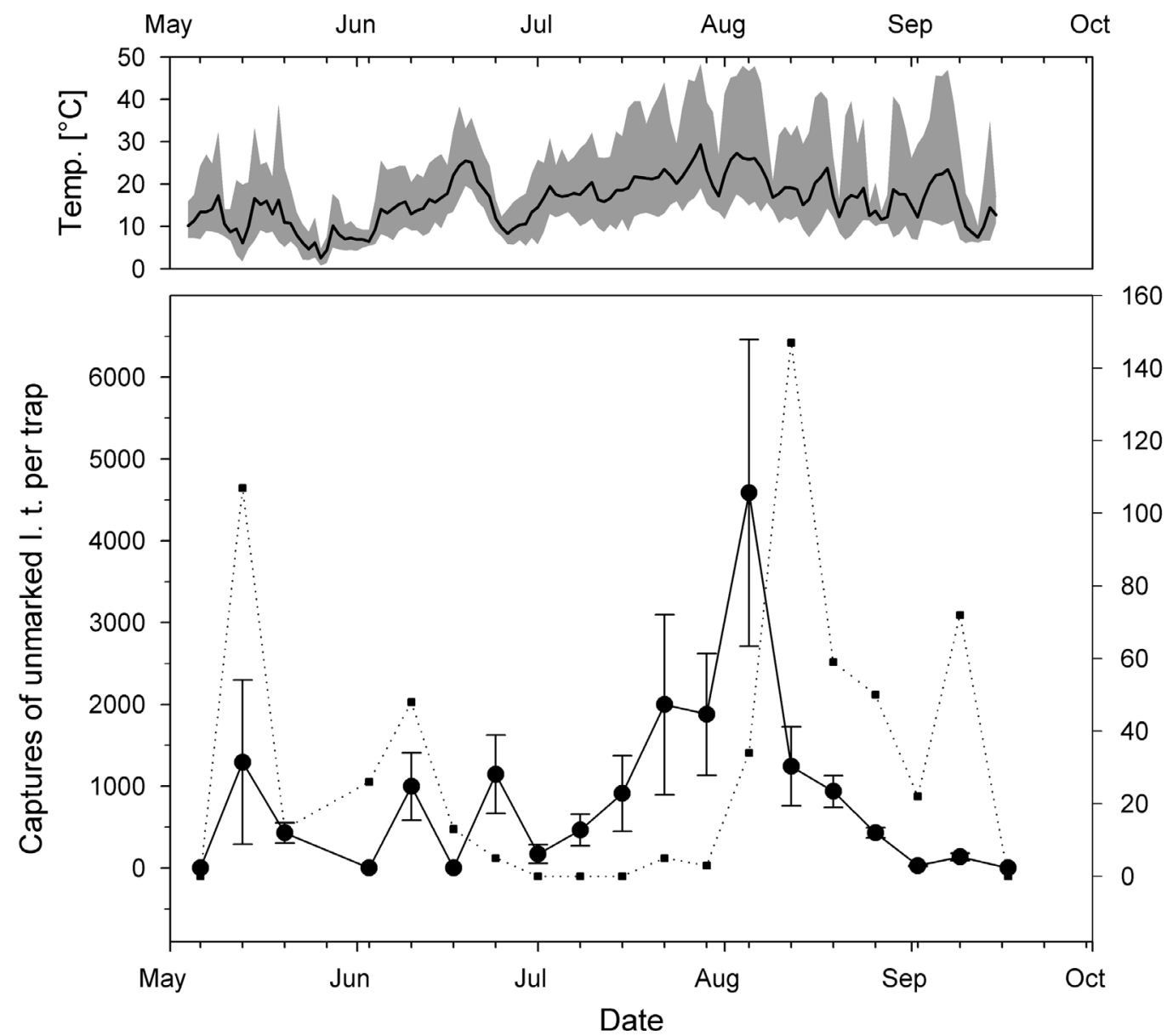

Fig. 2. Spruce bark beetle, Ips typographus, (I.t.) density (circles \pm S.D., connected with solid line) expressed as average number of beetles captured per pheromone baited slit trap together with absolute counts of marked beetles recaptured (squares connected with dotted line) during 2013. In the upper part, range in daily temperature (grey area) is plotted together with average daily temperatures.

beetles captured by the traps in each group were divided by the respective number of traps.

The direction in which most Ips typographus dispersed was evaluated using $\chi^{2}$ tests. Numbers captured at $50 \mathrm{~m}$ and $100 \mathrm{~m}$ in spring and summer were evaluated separately assuming they dispersed uniformly in all directions. To evaluate the sex ratios of beetles that dispersed over various distances, captured marked

Table 1. Beginning and end dates of trap monitoring, approximate numbers of marked beetles released and numbers of marked beetles captured during the spring and summer swarming at the experimental site in 2013 together with estimated dispersion model parameters and estimated median (ED50) and upper 10\% quantile (ED10) of dispersion distances of the marked beetles.

\begin{tabular}{lcc}
\hline & \multicolumn{2}{c}{ Swarming } \\
\cline { 2 - 3 } & spring & summer \\
\hline Beginning & $16^{\text {th }}$ May & $23^{\text {rd }}$ July \\
End & $27^{\text {th }}$ June & $10^{\text {th }}$ September \\
Marked Ips typographus & & \\
$\quad$ released (approx.) & 25000 & 20000 \\
$\quad$ captured & 215 & 385 \\
Dispersion model & & \\
parameter a & 76.185 & 85.597 \\
parameter $b$ & 0.1548 & 0.1658 \\
$\quad$ variance explained & $99.9 \%$ & $79.6 \%$ \\
$\quad$ ED10 & $555 \mathrm{~m}$ & $432 \mathrm{~m}$ \\
$\quad$ ED50 & $86 \mathrm{~m}$ & $76 \mathrm{~m}$ \\
\hline
\end{tabular}

beetles were dissected and their sex determined. Traps were divided into categories based on their distance from the release point and their captures pooled. A $\chi^{2}$-test was used to test the statistical difference between the actual sex ratio and a $1: 1$ sex ratio (Zumr, 1995; Lobinger, 1996).

$\chi^{2}$ tests were performed using STATISTICA 12 (Dell, 2015) and no family-wise error correction for multiple tests was applied.

\section{RESULTS}

Overwintered adults of Ips typographus started to fly in the second week of May. At that time, the number exceeded 1200 unmarked beetles per trap per week (BTW). Low temperatures and rainy weather during the following weeks interrupted the swarming for almost a month during which very few beetles were caught. The swarming then resumed from the second week of June until the end of the month. The average numbers caught were around 1000 BTW. The adults of the filial generation were first caught at the end of July and a maximum number of almost 7000 BTW was recorded at the beginning of August. The activity gradually decreased thereafter and the last capture of approximately 100 BTW was recorded on September 9, 2013 (Fig. 2).

The captures of marked beetles correlated with the general pattern of bark beetle activity (Fig. 2). The only exception occurred at the end of the growth season, when 


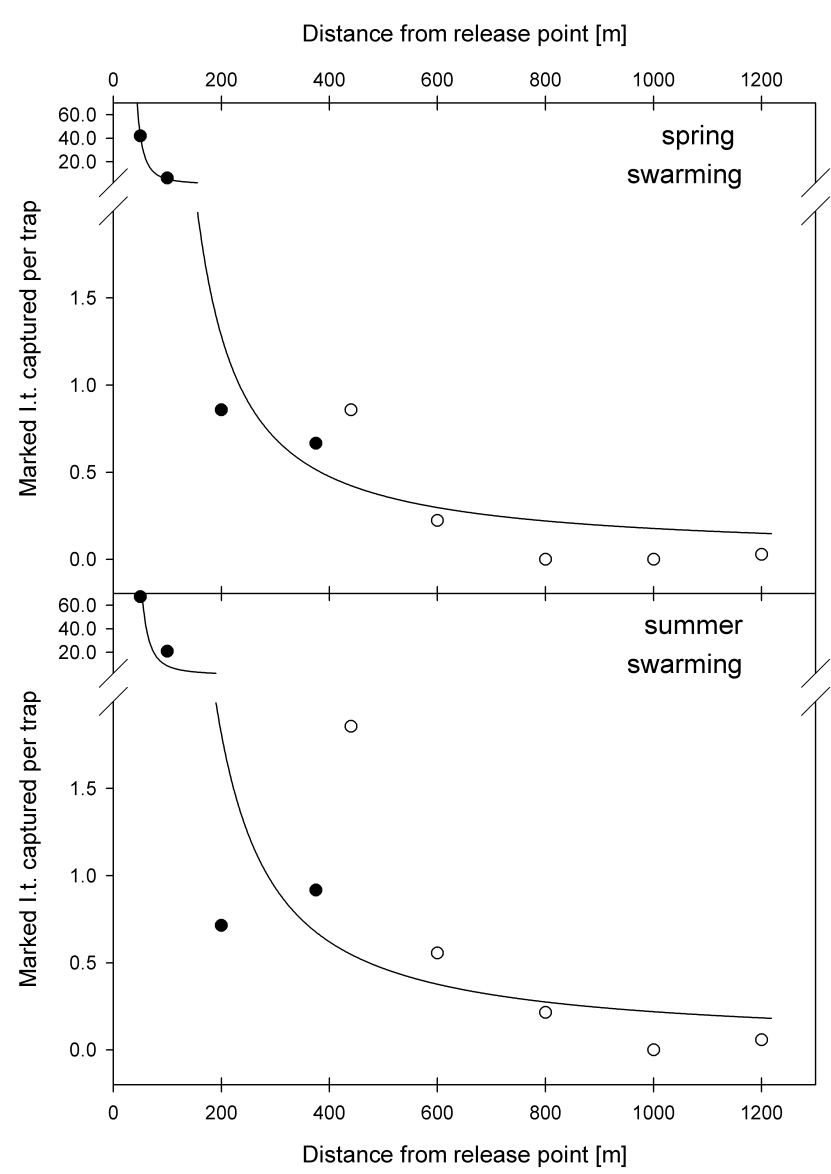

Fig. 3. Counts of marked spruce bark beetles, Ips typographus, (I.t.) caught per trap at various distances from the release point in unmanaged (closed circles) and managed areas (open circles) during the spring (top) and the summer (bottom) swarming in 2013 Closed circles were fitted by the model (solid line). See Material and methods section and Table 1 for more details.

an extraordinarily high percentage of marked beetles was recorded.

The total numbers of spruce bark beetles captured, estimated numbers of beetles released and length of the periods sampled during the spring and summer swarming are summarized in Table 1.

A total of 600 marked Ips typographus were captured during this study and the maximum distance flown recorded for a marked beetle was $1094 \mathrm{~m}$. Fitted models for the dispersal of Ips typographus during spring and summer swarming periods are presented in Fig. 3, which indicates that $10 \%$ of the marked beetles in the spring and summer swarmingflew more than $555 \mathrm{~m}$ and $432 \mathrm{~m}$, respectively.

More than $70 \%$ of the beetles captured were found in traps that were more than $50 \mathrm{~m}$ from the release point. In addition, the $200 \mathrm{~m}$ trap circle captured surprisingly few
Table 3. Percentage of females and the number of marked beetles recaptured in pheromone baited traps at various distances around the release point that were dissected. The $1: 1$ sex ratio was tested using $a x^{2}$ test and $x^{2}$ and $p$ are included for reference. Asterisk indicates a statistically significant difference at $\alpha=0.05$.

\begin{tabular}{ccccc}
\hline $\begin{array}{c}\text { Distance } \\
(\mathrm{m})\end{array}$ & $\begin{array}{c}\text { Females } \\
(\%)\end{array}$ & $\begin{array}{c}\text { Dissected } \\
\text { Ips typographus }\end{array}$ & $\mathrm{x}^{2}$ & $\mathrm{p}$ \\
\hline $0-50$ & 57.1 & 340 & 6.78 & $0.009^{*}$ \\
$50-100$ & 59.8 & 102 & 3.92 & $0.048^{*}$ \\
$100-200$ & 55.6 & 9 & 0.11 & 0.73 \\
$200-300$ & 33.3 & 6 & 0.66 & 0.41 \\
$300-400$ & 50.0 & 26 & 0 & 1 \\
\hline
\end{tabular}

marked beetles ( 6 and 5 beetles, respectively, in the spring and summer swarming).

Catches of marked beetles in neighboring managed stands grouped according to the distances from the release point are depicted together with the model estimates in Fig. 3.

Beetles did not disperse uniformly in all directions, with the north and north-east directions the most commonly recorded (see Table 2).

The sex ratio of recaptured beetles was significantly female biased $(57 \%$ and $60 \%)$ at short distances (50 or 100 $\mathrm{m}$, respectively) from the release point. However, at greater distances the sex ratio was not significantly different from a $1: 1$ ratio (see Table 3 ).

\section{DISCUSSION}

Bark beetle dispersal is influenced by numerous internal (e.g. weight, size, energetic status, population origin - non epidemic vs. epidemic, reaction to visual stimuli etc.) and external factors (e.g. breeding site availability, presence of volatile attractants, temperature, wind etc.) (Franklin \& Grégoire, 1999; Wichmann \& Ravn, 2001; Campbell \& Borden, 2009; Dworschak et al., 2011; Kautz et al., 2011b). The different flight patterns recorded for adults of non-epidemic and epidemic populations are discussed by numerous authors and a possible explanation can be summarized as an interplay between food and breeding source availability, energy reserves (competition) of migrating specimens and presence/absence of either primary or secondary attractants (Weslien \& Lindelöw, 1990; Safranyik et al., 1992; Franklin \& Grégoire, 1999; Kautz et al., 2011b). The frequency of different flight distances recorded at the site studied decreases exponentially with the distance from the release point. This indicates that higher population densities effectively reduce the average flight distance and beetles search for a host tree close to the original infestation. High numbers of beetles during outbreaks

Table 2. Directional uniformity of Ips typographus dispersal. Summary of the statistics of uniformity of dispersal ( $X^{2}$, df and $\left.p\right)$ together with the most commonly recorded (MOD) and the least commonly recorded directions (LOD). N - northward, S - southward, E - eastward, W - westward.

\begin{tabular}{|c|c|c|c|c|c|c|c|c|c|c|}
\hline & \multicolumn{5}{|c|}{ Spring swarming } & \multicolumn{5}{|c|}{ Summer swarming } \\
\hline & $x^{2}$ & df & $p$ & MOD & LOD & $x^{2}$ & $\mathrm{df}$ & $p$ & MOD & LOD \\
\hline $50 \mathrm{~m}$ & 84.6 & 3 & $<10^{-6}$ & $\mathrm{~N}$ & $\mathrm{~S}+\mathrm{W}$ & 41.3 & 3 & $<10^{-6}$ & $\mathrm{~N}$ & $\mathrm{~S}$ \\
\hline $100 \mathrm{~m}$ & 7.33 & 3 & 0.06 & SE & $\mathrm{NW}+\mathrm{SW}$ & 54.5 & 3 & $<10^{-6}$ & $\mathrm{NE}$ & SE \\
\hline
\end{tabular}


probably ensure that even healthy trees with strong defense are unable to withstand the attack. The attractiveness of such trees is gradually increased due to the aggregation pheromone produced by each adult that lands on the trees (Franklin \& Grégoire, 1999). Infesting the nearest tree is also more advantageous because of the energy demands of flight, although a direct relationship between the total lipid content and flight distance has never been proved (Botterweg, 1982; Dworschak et al., 2011).

The marking and fluorescent detection used in the present study is a unique combination of known methods and a novel application of others. The large scale labelling of $\log$ is fast (using suitable dusters) and only a dust-protection mask and protective overalls are needed. The dye used is non-toxic and, because of its fine grain size, it is unlikely to interfere with insect flight capabilities. Construction of tin roof shelters to prevent the dye being washed off by rain reduces the need for reapplication. We employed, to our knowledge, a unique and simple conversion of a cheap handheld lamp with a CREE LED into a fluorescence detector by refitting it with a LED source of defined emission spectra suitable for excitation of the whole range of JST series of fluorescent powders. It offers several advantages compared to other methods. Mainly, there is no potentially harmful blacklight and the light source is cheap (1W LED is about 10 USD and the lamp is another 15 USD). The yellow goggles are a very beneficial and inexpensive (from 2 USD) replacement for costly low/band-pass filters and can be used for detection of all emission colors except blue. On the other hand, employment of hand-held violet or blue lasers could enable detection from greater distances (Rice et al., 2015).

The bark beetle dispersion model employed here can predict dispersal patterns at greater distances than the more generally accepted models (Turchin \& Thoeny, 1993; Duelli et al., 1995) on which it is based. The present model uses data recorded within unmanaged forest, which borders on managed stands, where pheromone baited slit-traps were used as a monitoring and protective measure. The capture of marked beetles in these traps were compared to the captures predicted by the dispersion model. It is clear that, at shorter distances (in this case, $440 \mathrm{~m}$ ), the risk of Ips typographus spreading from an unmanaged to a managed area was higher than predicted by the model, whilst at greater distances $(>800 \mathrm{~m})$, the risk of Ips typographus dispersion was lower than predicted. Such information is of importance for foresters planning protective measures against the spruce bark beetle. We confirm previous practical experiences in the Bavarian Forest NP (Heurich et al., 2001) and Harz NP (Niemeyer et al., 1995) that the spread of beetles from unmanaged areas with a high population density to managed stands can effectively be prevented by buffer zones located within 100-1500 m. Our model suggests that stands at distances of more than $500 \mathrm{~m}$ should be at less risk of infestation and, therefore, it can be concluded that $500 \mathrm{~m}$ protective zones should effectively reduce the number of migrating beetles. This finding is in agreement with those of Kautz et al. (2011b) and Lausch et al.
(2011, 2013) who record that $95 \%$ of the new infestations occurred within $500 \mathrm{~m}$. Similar conclusions are drawn by authors that recently studied the question of spruce bark beetle population levels in unmanaged and surrounding managed forests. Generally, it can be concluded that under non-epidemic conditions, unmanaged stands do not necessarily pose a threat to surrounding managed forests (Schlyter \& Lundgren, 1993). However, rapid population growth in unmanaged stands may threaten neighboring managed forests at distances of up to $500 \mathrm{~m}$ following abiotic disturbances (e.g. storms or drought) (Wichmann \& Ravn, 2001).

The present model estimated that approximately $10 \%$ of beetles migrated for distances of more than $500 \mathrm{~m}$, which corresponds with the results of Wichmann \& Ravn (2001), who report that $90 \%$ of new infestations occurred within $100 \mathrm{~m}$ of previous infestations. Thus, it can be concluded that the percentage of long-distance flyers in a population varies between the above mentioned $10 \%$ and the figure of $50 \%$ estimated by Duelli et al. (1995). That beetles that overwinter (spring swarming) fly greater distances is also reported (Furuta et al., 1996). The higher tendency for the overwintered generation to migrate may be attributed to the resumption of direct development following overwintering and the necessity for these beetles to replenish energy reserves and search for new breeding sites. Such behavior is common in many other species of insects (Košt’ál, 2006). The maximum distances flown by the spruce bark beetle recorded in the present study and those reported in other studies are very convincing, regardless of differences in the methods used. The most distant catches of marked beetles recorded in this study were almost $1100 \mathrm{~m}$ from the release point. Zumr (1990, 1991, 1993) recaptured marked spruce bark beetles at distances up to $1200 \mathrm{~m}$ regardless of forest structure and composition, whilst Weslien \& Lindelöw (1990) recaptured $2 \%$ at $1200-1600 \mathrm{~m}$. Therefore, it can be concluded that a significant percentage migrate longer distances. This observation might explain the occasional observations of mass infestations at localities where bark beetles were not previously reported by foresters. This information may also be of practical importance. Currently, the most widely used protective measures employed against the spruce bark beetle include timely removal of potential breeding material and sanitation felling of infested trees (Wermelinger, 2004). Various trapping devices (e.g. trap trees, poisoned trap trees, pheromone traps etc.) are also being installed in order to prevent attacks on living trees in the sanitation felling area. Although relevant legislation differs between European countries, the exact number of trapping devices deployed usually depends on the number of infested trees that were found and felled on site during the preceding period. Based on the results of this study, some trapping devices should be installed across a wider area (as permitted by terrain/ canopy configuration) to restrict the spread of an infestation.

The low catch of the traps in the $200 \mathrm{~m}$ trap circle (6 and 5 beetles, respectively, in the spring and summer swarming) recorded in this study can be attributed to the fact 
that most of the traps in this circle were located inside the canopy or at the boundary between living and dead standing forest. Relatively high catches of marked beetles at the end of the growth season compared to the general activity and catches of unmarked beetles were probably due to the fact that the bark of the logs at the release point was too disturbed by previous development and feeding to provide a suitable overwintering habitat for the remaining beetles. The adults were thus forced to emerge and search for a new habitat in which to overwinter. Such behaviour is common to most pre-diapause insects (Koštál, 2006).

In traps closer to the release point, more marked female beetles were captured than males. A reproductively successful male usually mates with two to three females (Wermelinger, 2004). Males also initiate colonization of a new host tree. Therefore, a greater flight distance of males is to be expected. Unfortunately, there were too few captures at the greater distances to show if there was any significant departure from a 1:1 sex ratio (Zumr, 1995; Lobinger, 1996). However, higher captures of females at closer distances may indicate either that males had dispersed further or were not as attracted by synthetic pheromones as females. A lower percentage of males in pheromone trap catches has previously been mentioned by many authors (Annila, 1971; Zumr, 1982; Lindelöw \& Weslien, 1986; Schlyter et al., 1987; Weslien \& Bylund, 1988). Another possible explanation might be a higher percentage of females developing during periods of high population density. Such a shift in sex ratio (up to $70 \%$ females) is reported by Lobinger (1996) in Southern Bavaria.

Although wind speed/direction data were recorded during this study, the resolution of beetle collections (once or twice a week) did not enable a direct comparison of wind speed/direction and position of the marked individuals captured. The fact that beetles did not disperse uniformly in all directions can most probably be attributed to variations in the attractiveness of different areas of the forest. The managed forests in the eastern part of the study area consisted of numerous sunlit stand edges, which would be attractive to bark beetles, whilst the unmanaged stands were characterized by a very high and increasing proportion of dead trees.

ACKNOWLEDGEMENTS. This research was by supported by a project in the framework of the Operation Programme "CrossBorder Cooperation Austria - Czech Republic" of the European Union's European Regional Development Fund, by project LH 12098 from the Ministry of Education, Youth and Sports, and by project 08/2009 from the Forests of the Czech Republic, state enterprises. We would like to thank B. Miklas, M. Moravcová, O. Vojtěch, V. Plchotová and students from the Gymnázium J. Ortena Kutná Hora for the support in the field. The authors would also like to thank C. Stauffer and Y. Moodley for their help with experimental design, two anonymous reviewers, whose comments considerably increased the quality of the manuscript and G. Small and A.F.G. Dixon for English correction.

\section{REFERENCES}

AnNILA E. 1971: Sex-ratio in Ips typographus L. (Col., Scolytidae). - Ann. Entomol. Fenn. 37: 7-14.
BotTerweg P. 1982: Dispersal and flight behavior of the spruce bark beetle Ips typographus. - J. Appl. Entomol. 94: 466-489.

BYERS J.A. 1996: An encounter rate model of bark beetle populations searching at random for susceptible host trees. - Ecol. Model. 91: 57-66.

BYERS J.A. 2000: Wind-aided dispersal of simulated bark beetles flying through forests. - Ecol. Model. 125: 231-243.

Campbell S.A. \& Borden J.H. 2009: Additive and synergistic integration of multimodal cues of both hosts and non-hosts during host selection by woodboring insects. - Oikos 118: 553-563.

Dell Inc. 2015: STATISTICA Data Analysis Software System.Ver. 12. www.statsoft.com

Duelli P., Zahradnik P., Knizek M. \& Kalinova B. 1997: Migration in the spruce bark beetle (Ips typographus L.) and the efficiency of pheromone traps. - J. Appl. Entomol. 121: 297-303.

Dworschak K., Kautz M. \& Schopf R. 2011: Are dispersal and infestation distances in Ips typographus limited by energy reserves? In: Book of Abstracts, Meeting of German Society of General and Applied Entomology (DGaaE), Entomologentagung, Berlin, Germany, March 21-24, 2011. p.146.

FLEISCHER A. 1875: Lýkožrouti čili korovci (Bostrychus typographus L.) v Šumavě a jich neprátelé. [Bark beetles (Bostrychus typographus L.) and their natural enemies in Sumava mountains] - Vesmir 4: 97-99, 111-114, 128-129 [in Czech].

Forsse E. \& Solbreck C. 1985: Migration in the bark beetle Ips typographus L.: duration, timing and height of flight. $-Z$. Angew. Entomol. 100: 47-57.

FORSTER B. 1993: Development of the bark beetle situation in the Swiss storm-damage areas. - Schweiz. Z. Forstwes. 144: 767-776.

Franklin A.J. \& GRÉGOIRE J.-C. 1999: Flight behaviour of Ips typographus L. (Col., Scolytidae) in an environment without pheromones. - Ann. For. Sci. 56: 591-598.

Franklin A.J., Debruyne C. \& Grégoire J.-C. 2000: Recapture of Ips typographus L. (Col., Scolytidae) with attractants of low release rates: localized dispersion and environmental influences. - Agr. For. Entomol. 2: 259-270.

Furuta K., Iguchi K. \& Lawson S. 1996: Seasonal difference in the abundance of the spruce beetle (Ips typographus japonicas Niijima) (Col., Scolytidae) within and outside forest in a bivoltine area. - J. Appl. Entomol. 120: 125-129.

HAWKes C. 2009: Linking movement behaviour, dispersal and population processes: is individual variation a key? - J. Anim. Ecol. 78: 894-906.

Heurich M., Reinelt A. \& Fahse L. 2001: Die Buchdruckermassenvermehrung im Nationalpark Bayerischer Wald. In: Heurich M. (ed.): Waldentwicklung im Bergwald nach Windwurf und Borkenkäferbefall. Vol. 14. Bayer, Staatsforstverwaltung Wiss. Reihe, Grafenau, pp. 9-48.

Hietz P., Baier P., Offenthaler I., Führer E., Rosner S. \& RichTER H. 2005: Tree temperatures, volatile organic emissions, and primary attraction of bark beetles. - Phyton - Ann. Rei Bot. 45: 341-354.

Kautz M., Duell J. \& Ohser J. 2011a: Spatial dependence of random sets and its application to dispersion of bark beetle infestation in a natural forest. - Image Anal. Ster. 30: 123-131.

Kautz M., Dworschak K., Gruppe A. \& Schopf R. 2011b: Quantifying spatio-temporal dispersion of bark beetle infestations in epidemic and non-epidemic conditions. - For. Ecol. Manag. 262: 598-608.

Knoke T., Stimm B., Ammer C. \& Moog M. 2005: Mixed forests reconsidered: A forest economics contribution on an ecological concept. - For. Ecol. Manag. 213: 102-116. 
KoMÁREK J. 1931: Mnišková kalamita v letech 1917-1927. [The Nun Moth Outbreak in 1917-1927.] Ministry of Agriculture, Prague, 256 pp. [in Czech].

KošŤÁL V. 2006: Eco-physiological phases of insect diapause. J. Insect Physiol. 52: 113-127.

Lausch A., Fahse L. \& Heurich M. 2011: Factors affecting the spatio-temporal dispersion of Ips typographus (L.) in Bavarian Forest National Park: A long-term quantitative landscape-level analysis. - For. Ecol. Manag. 261: 233-245.

Lausch A., Heurich M. \& Fahse L. 2013: Spatio-temporal infestation patterns of Ips typographus (L.) in the Bavarian Forest National Park, Germany. - Ecol. Indic. 31: 73-81.

Lindelöw A. \& Weslien J. 1986: Sex-specific emergence of Ips typographus L. (Coleoptera: Scolytidae) and flight behavior in response to pheromone sources following hibernation. - Can. Entomol. 118: 59-67.

LOBINGER G. 1996: Variations in sex ratio during an outbreak of Ips typographus (Col., Scolytidae) in Southern Bavaria. Anz. Schädlingsk. Pflanzensch. Umweltsch. 69: 51-53.

Mansfeld V. 2011: Norway spruce in forest ecosystems of the Czech Republic in relation to different forest site conditions. — J. For. Sci. 57: 514-522.

Niemeyer H., Ackermann J. \& Watzek G. 1995a: Eine ungestörte Massenvermehrung des Buchdruckers (Ips typographus) im Hochharz. - Forst Holz 50: 239-243.

NiLSSEN A.C. 1984: Long-range aerial dispersal of bark beetles and bark weevils (Coleoptera, Scolytidae and Curculionidae) in northern Finland. - Ann. Entomol. Fenn. 50: 37-42.

NuORTEVA M.K. 1955: Kirjanpainaja (Ips typographus L.) kuusirajan pohjoispuolelta [The bark beetle, Ips typographus, found beyond the northern range of the spruce]. - Ann. Entomol. Fenn. 21: 195-196 [in Finnish].

OKrouhlík J. \& Foltán P. 2015: Evaluation of the diet of a predator using fluorescent marking of prey. - Eur. J. Entomol. 112: $477-485$.

RAFFA K. \& Berryman A. 1982: Gustatory cues in the orientation of Dendroctonus ponderosae (Coleoptera: Scolytidae) to host trees. - Can. Entomol. 114: 97-104.

Reeve J.D. 1997: Predation and bark beetle dynamics. - Oecologia 112: 48-54.

Rice K.B., Fleischer S.J., De Moraes C.M., Mescher M.C., ToOKer J.F. \& Gish M. 2015: Handheld lasers allow efficient detection of fluorescent marked organisms in the field. $-P L o S$ ONE 10: e0129175.

Safranyik L., Linton D.A., Silversides R. \& McMullen L.H. 1992: Dispersal of released mountain pine beetles under the canopy of a mature lodgepole pine stand. - J. Appl. Entomol. 113: 441-450.

Schindelin J., Arganda-Carreras I. \& Frise E., Kaynig V., Longair M., Pietzsch T., Preibisch S., Rueden C., Saalfeld S., Schmid B., Tinevez J.Y., White D.J., Hartenstein V., Eliceiri K., TomancaK P. \& Cardona A. 2012: Fiji: an open-source platform for biological-image analysis. - Nature Methods 9: 676-682.

SChlyter F. \& Lundgren U. 1993: Distribution of a bark beetle and its predator within and outside old growth forest reserves: no increase of hazard near reserves. - Scand. J. For. Res. 8: 246-256.

SChlyter F., LÖFQvist J. \& Byers J.A. 1987: Behavioural sequence in the attraction of the bark beetle Ips typographus to pheromone sources. - Physiol. Entomol. 12: 185-196.
SCHWENKE W. von 1996: Principles of population dynamics and control of the great spruce bark beetle, Ips typographus. Anz. Schädlingsk. Pflanzensch. Umweltsch. 69: 11-15.

SPIECKER H. 2003: Silvicultural management in maintaining biodiversity and resistance of forests in Europe temperate zone. - J. Environ. Manag. 67: 55-65.

SzUJECKI A. 1987: Ecology of Forest Insects. Springer, Dordrecht, $602 \mathrm{pp}$.

Turchin P. \& Thoeny W.T. 1993: Quantifying dispersal of southern pine beetles with mark-recapture experiments and a diffusion model. - Ecol. Appl. 3: 187-198.

WERMELINGER B. 2004: Ecology and management of the spruce bark beetle Ips typographus - a review of recent research. For. Ecol. Manag. 202: 67-82.

Wermelinger B. \& SeIFERT M. 1999: Temperature-dependent reproduction of the spruce bark beetle Ips typographus, and analysis of the potential population growth. - Ecol. Entomol. 24: $103-110$.

Werner R.A. \& Holsten E.H. 1997: Dispersal of the Spruce Beetle, Dendroctonus rufipennis, and the Engraver Beetle, Ips perturbatus in Alaska. Res. Pap. PNW-RP-501, U.S. Department of Agriculture, Forest Service, Pacific Northwest Research Station, Portland, OR, 8 pp.

Weslien J. \& BYLund H. 1988: The number and sex of spruce bark beetle, Ips typographus (L.), caught in pheromone traps as related to flight season, trap type, and pheromone release. $-J$. Appl. Entomol. 106: 488-493.

WesLien J. \& Lindelöw A. 1990: Recapture of marked spruce bark beetles (Ips typographus) in pheromone traps using areawide mass trapping. - Can. J. For. Res. 20: 1786-1790.

Wichmann L. \& Ravn H.P. 2001: The spread of Ips typographus (L.) (Coleoptera, Scolytidae) attacks following heavy windthrow in Denmark, analysed using GIS. - For. Ecol. Manag. 148: 31-39.

Yousefpour R., Hanewinkel M. \& Moguédec G.L. 2010: Evaluating the suitability of management strategies of pure Norway spruce forests in the black forest area of southwest Germany for adaptation to or mitigation of climate change. - Environ. Manag. 45: 387-402.

Zolubas P. \& Byers J.A. 1995: Recapture of dispersing bark beetle Ips typographus L. (Col., Scolytidae) in pheromone baited traps: regression models. - J. Appl. Entomol. 119: 285-289.

ZumR V. 1982: On the sex-ratio of Ips typographus (L.) (Coleoptera, Scolytidae) in pheromone traps. - Anz. Schädlingsk. Pflanzensch. Umweltsch. 55: 68-71 [in German].

ZUMR V. 1990: Letová aktivita lýkožrouta smrkového Ips typographus (L.) v otevřené krajině. [Flight activity of the spruce bark beetle, Ips typographus (L.), in open area]. - Sbor. $\check{C} S A Z V$ Lesnictví 36: 221-228 [in Czech].

ZumR V. 1991: The behaviour of the spruce bark beetle Ips typographus (L.) (Coleoptera, Scolytidae) during dispersal phase in mixed forest stands. - Sbor. ĆSAZV Lesnictvi 37: 669-675.

ZumR V. 1992: Dispersal of the spruce bark beetle Ips typographus (L.) (Col., Scolytidae) in spruce woods. - J. Appl. Entomol. 114: 348-352.

ZuMr V. 1995: Lýkožrout smrkový - biologie, prevence a metody boje. [Biology, Prevention and Management of the Spruce Bark Beetle.]. Matice lesnická, Písek, 132 pp. [in Czech].

Received June 17, 2015; revised and accepted September 29, 2015 Published online January 7, 2016 